\title{
Acid-Base Balance and Arterial Ion Concentrations in Rat Under Three Types of General Anaesthesia: Chronobiological Study
}

\author{
Pavol Svorc ${ }^{1, ~ *, ~ D a r i n a ~ P e t r a s o v a ~}{ }^{2}$, Pavol Svorc $\mathrm{Jr}^{3}$ \\ ${ }^{1}$ Department of Physiology, Medical Faculty Safarik's University, Kosice, Slovak Republic \\ ${ }^{2}$ Laboratory of Research Bio-models, Medical Faculty Safarik's University, Kosice, Slovak Republic \\ ${ }^{3}$ Department of Physiology and Patophysiology, Medical Faculty Ostrava University, Ostrava, Czech Republic \\ Email address: \\ pavol.svorc@upjs.sk (P. Svorc) \\ ${ }^{*}$ Corresponding author
}

To cite this article:

Pavol Svorc, Darina Petrasova, Pavol Svorc Jr. Acid-Base Balance and Arterial Ion Concentrations in Rat Under Three Types of General Anaesthesia: Chronobiological Study. Advances in Applied Physiology. Vol. 3, No. 1, 2018, pp. 26-32. doi: 10.11648/j.aap.20180301.14

Received: May 27, 2018; Accepted: June 8, 2018; Published: July 9, 2018

\begin{abstract}
The design and development of experimental, in vivo, chronobiological animal models may help reveal some of the relationships between circadian rhythms and biological functions. In vivo experiments require the use of appropriate anaesthesia, which should be selected according to their particular effect on the organism. The aim of study was to review the status of acid-base balance and ion concentration in arterial blood under common used general anaesthesias in experiments in dependence on the light-dark (LD) cycle in spontaneously breathing rats. The experiments were performed using three- to four-month-old pentobarbital (P)-, ketamine/xylazine (K/X)- and zoletil ( $\mathrm{Z}$ )-aneasthetized female Wistar rats after a four-week adaptation to an LD cycle (12h light:12h dark). It was concluded that $P$ anaesthesia disturbs LD dependence of acid-base balance compared to $\mathrm{K} / \mathrm{X}$ and $\mathrm{Z}$ anaesthesia, but $\mathrm{LD}$ differences in plasma ion concentrations are disturbed under all type of general anaesthesia. $\mathrm{P}$ anaesthesia is not the most appropriate type of anaesthesia in rat chronobiological experiments. It eliminated LD differences, and also produces a more acidic environment, more pronounced hypercapnia and hypoxia than $\mathrm{K} / \mathrm{X}$ and $\mathrm{Z}$ anaesthesias. This should be taken into account because the altered internal environment may affect the activity of systems whose functions are primarily dependent on acid-base balance or/and ion concentrations.
\end{abstract}

Keywords: Chronobiology, Anaesthesia, Acid-Base Balance, Ions, Rats

\section{Introduction}

Rats are useful models to study functions of various systems in preclinical trials and toxicological studies [1]. Normative data for $\mathrm{pH}$, arterial blood gases and electrolytes would help identify healthy animals for the experiments. However, there are few studies that have investigated the reliability of this tool [2]. Table 1 and 2 summarize acid-base parameters and ion arterial concentration from rats reported by several authors. However, the time when the experiments were performed and the synchronization of the animals to the light-dark (LD) cycle were not accounted for in the methodologies of these studies.

Table 1. Values of $p H$, blood gases, and bicarbonate in the arterial blood of rats published in previous studies.

\begin{tabular}{lllll}
\hline \multicolumn{1}{c}{ Author (year) } & \multicolumn{1}{c}{$\mathbf{p H}$} & \multicolumn{1}{c}{$\mathbf{p C O}_{\mathbf{2}} \mathbf{( k P a )}$} & \multicolumn{1}{c}{$\mathbf{p O}_{\mathbf{2}} \mathbf{( k P a )}$} & $\mathbf{H C O}_{3}{ }^{-} \mathbf{~ m m o l} / \mathbf{I}$ \\
\hline Lewis et al. [3] & 7.43 & 5.7 & 12.13 & \\
Pepelko and Dixon [4] & $7.446-7.486$ & $5.24-5.74$ & $11.77-12.71$ & $24-27$ \\
Brun-Pascaud et al. [5] & $7.45-7.49$ & $4.2-4.99$ & $11.26-12.72$ & $25-25.8$ \\
Girard et al. [6] & $7.46-7.47$ & $4.57-4.71$ & $12.72-13.02$ & \\
Hess et al. [7] & $7.43-7.51$ & $3.33-4.67$ & $12.2-15.4$ & \\
Dettmers [8] & $7.38-7.46$ & $5.19-5.99$ & $9.4-11$ & \\
\hline
\end{tabular}




\begin{tabular}{|c|c|c|c|c|}
\hline Author (year) & pH & $\mathrm{pCO}_{2}(\mathrm{kPa})$ & $\mathrm{pO}_{2}(\mathrm{kPa})$ & $\mathrm{HCO}_{3}{ }^{-} \mathrm{mmol} / \mathrm{I}$ \\
\hline Chi et al. [9] & $7.27-7.37$ & $4.78-5.77$ & $13.8-17$ & \\
\hline Ohoi and Takeo [10] & & $4.66-5.32$ & $13.3-17.3$ & \\
\hline Schultz [11] & $7.35-7.45$ & $3.33-5.32$ & $10.6-14.6$ & \\
\hline Sun and Wainwright [12] & $7.40-7.45$ & $4.64-5.32$ & 11.3 & \\
\hline Forkel [13] & & $5.16-6.39$ & $12.85-15.48$ & \\
\hline Valenza et al. [14] & $7.41-7.43$ & $5.18-5.48$ & & $25.3-27.1$ \\
\hline Subramanian et al. [1] & $7.26-7.4$ & $5.05-7.51$ & $10.76-14.60$ & $21.5-28.1$ \\
\hline Peralta-Ramírez [15] & $7.2-7.46$ & $5.62-6.20$ & & $23.2-25.8$ \\
\hline Luo et al. [16] & & $5.58-6.08$ & $10.37-12.19$ & \\
\hline
\end{tabular}

Table 2. Arterial plasma ion concentrations in the arterial blood of rats published in previous studies.

\begin{tabular}{|c|c|c|c|c|}
\hline Author & $\mathrm{Na}^{+}(\mathrm{mmol} / \mathrm{l})$ & $\mathrm{K}^{+}(\mathrm{mmol} / \mathrm{l})$ & $\mathrm{Ca}^{2+}(\mathrm{mmol} / \mathrm{l})$ & $\mathrm{Cl}^{-}(\mathrm{mmol} / \mathrm{l})$ \\
\hline Menegon et al. [17] & $142.1-143.9$ & $3.6-3.8$ & & \\
\hline Da Silva Costa et al. [18] & 138.9-141.1 & $4.74-4.86$ & $6.72-7.38$ & \\
\hline Valenza et al. [14] & $132.4-140$ & $4.1-4.42$ & & $102.9-107.7$ \\
\hline Subramanian et al. [1] & $140.7-145.6$ & $3.08-4.02$ & & \\
\hline Peralta-Ramírez et al. [15] & 134.6-137.3 & $3.93-4.25$ & $1.23-1.29$ & $104.4-108.1$ \\
\hline Kim et al. [19] & $135.6-136.4$ & $3.7-3.9$ & & \\
\hline
\end{tabular}

Although chronobiological studies investigating the interactions between general anaesthesia and circadian rhythms are sparse, all suggest that general anaesthesia has a significant effect on vital functions [20]. However, to date, there is no literature evidence regarding the effect of general anaesthesia on acid-base balance and ion concentration in arterial blood and their dependence on circadian rhythmicity or the light-dark (LD) cycle.

Chronobiological aspects can also be the problem originating from the circadian rhythm [21, 22]. Most methods do not describe the time of day at which the experiments were carried out on the factors responsible for the changes in the particular parameters studied mainly focused on the temporally current mechanical and metabolic changes, often irrespective of the functional state of systems in a 24-h period. This can be problem because, for example, the light-dark cycle (LD cycle) is the strongest factor in the synchronization of endogenous rhythms in rats.

The choice of anaesthetic agent and its influence (particularly on respiratory and cardiovascular system [23, 24] can be problematic. Changes in the functional efficiency of these systems lead to changes in acid-base balance and conversely, changes in acid-base balance influence the functional state of these systems. Similarly, changes in acid-base balance also reflect the 24-h fluctuation in the functions of respiratory and cardiovascular systems. Hence, the reference values of acid-base balance can cause difficulties because acid-base balance reflects the current (active or non-active) state of the organism. Results are often compared with mean reference values, often irrespective of the dependence of circadian rhythm. Usually, the time when the experiments were performed and the synchronization of the animals to the light-dark (LD) cycle were not accounted for in the methodologies of these studies.

These possible problems elicit more questions:

i. are reference values for acid-base balance parameters correct?

ii. when (time of day) and under which conditions (conscious state or under anaesthesia) was the analysis of acid-base balance undertaken?

The specific aim of the present in vivo study, therefore, was to refer to initial values in some acid-base parameters and arterial ion concentration in spontaneously breathing pentobarbital-, ketamine-xylazine and zoletil-anaesthetized rats. This information will contribute to a framework for a chronobiological perspective on the dependence of these parameters on the light-dark (LD) cycle under in vivo conditions.

\section{Material and Methods}

The present study conformed to the Guide for the Care and Use of Laboratory Animals published by the United States National Institutes of Health (NIH publication number 85-23, revised 1996). The study protocol was approved by the Ethics Committee of the Medical Faculty of Safarik University (Kosice, Slovak Republic) (permission number 2/05 and permission number ŠVPS SR: Ro-4234/15-221).

The present study was performed using female Wistar rats (mean $[ \pm \mathrm{SD}]$ weight $310 \pm 20 \mathrm{~g}$, three to four months of age after adaptation to an LD cycle (12h light:12h dark [intensity of artificial illumination $80 \mathrm{Lux}$ ]; $40 \%$ to $60 \%$ humidity; cage temperature $24^{\circ} \mathrm{C}$; two animals/cage; ad libitum access to food and water) for four weeks. The effect of the light period on the monitored parameters was examined after adaptation to an LD cycle, with the light period from 06:00 h to 18:00 h. The effect of the dark period was monitored after adaptation to the inverse setting of the LD cycle (i.e., with the light period from 18:00 h to $06: 00 \mathrm{~h}$ ).

The animals were divided into three experimental groups according to the anaesthetic agent used. Group 1 pentobarbital intraperitoneal anaesthesia $(40 \mathrm{mg} / \mathrm{kg}$, Spofa, Prague), light period $n=16$, dark period $n=27$, group 2 ketamine $(100 \mathrm{mg} / \mathrm{kg}$, Narkamon, Spofa, Prague $)+$ xylazine (15mg/kg, Rometar, Spofa, Prague) intramuscular anaesthesia, light period $n=11$, dark period $n=13$ and group 3 - zoletil (30mg/kg, Virbac, France) intraperitoneal anaesthesia, light period $n=10$, dark period $n=12$. 
Animals, $20 \mathrm{~min}$. after administration of anaesthetic agent, were fixed to a experimental table at spontaneous breathing in the supine position. Parameters of acid-base balance and ions were analyzed from blood samples taken from the femoral artery using radiometer ABL 800 Flex (Copenhagen, Denmark) in Department of Laboratory Medicine in Faculty Hospital Louis Pasteur in Kosice. The depth of anaesthesia was examined such that painful stimuli did not evoke noticeable motor or cardiovascular responses.

Statistical analysis

Data are presented as mean $\pm \mathrm{SD}$. The data were analyzed using GraphPad InStat (GraphPad Software, USA). ANOVA was applied to detect significant differences within a single end point. The Tukey-Kramer test was used to identify significant differences between groups; $p<0.05$ was considered to be statistically significant. The experiments were performed during the entire year and the results were averaged independent of seasons.

\section{Results}

\section{1. $\mathrm{pH}$}

Under $\mathrm{P}$ anaesthesia, significant LD differences in arterial $\mathrm{pH}$ were not found, and values remained at the same (moderate acidic) levels. Under $\mathrm{K} / \mathrm{X}(\mathrm{p}<0.001)$ and $\mathrm{Z}(\mathrm{p}<$ 0.001 ) anaesthesias, the $\mathrm{pH}$ was significantly higher in the dark (active) versus the light part of the rat regimen day (table 3 ). In the light part of the day, the $\mathrm{pH}$ values reflect acidosis, compared with the range calculated from other authors $(\mathrm{pH}$ ranges from 7.37 to 7.45 from table 1) in all types of anaesthesia, and there was no significant difference between individual types of anaesthesia. In the dark part of the day, mean $\mathrm{pH}$ values were significantly higher in $\mathrm{K} / \mathrm{X}(\mathrm{p}<0.05)$ and $\mathrm{Z}(\mathrm{p}<0.05)$ anaesthesias compared with $\mathrm{P}$ anesthesia. In this part of the day, the $\mathrm{pH}$ was within the normal range under $\mathrm{Z}$ anaesthesia and even reached an alkaline state in $\mathrm{K} / \mathrm{X}$ anaesthesia.

Table 3. Ph, blood gases and acid-base parameters and ion concentrations from arterial blood under selected types of anaesthesia during the light and dark periods of the rat regimen day.

\begin{tabular}{|c|c|c|c|c|c|c|}
\hline & \multicolumn{2}{|c|}{ Pentobarbital } & \multicolumn{2}{|c|}{ Ketamine/ xylazine } & \multicolumn{2}{|l|}{ Zoletil } \\
\hline & Light & Dark & Light & Dark & Light & Dark \\
\hline $\mathrm{pH}$ & $7.314 \pm 0.04$ & $7.331 \pm 0.04$ & $7.326 \pm 0.04$ & $7.491 \pm 0.06 * * *$ & $7.317 \pm 0.05$ & $7.384 \pm 0.06^{* * *}$ \\
\hline $\mathrm{pCO}_{2}(\mathrm{kPa})$ & $8.35 \pm 1.03$ & $8.64 \pm 1.49$ & $6.762 \pm 1.84$ & $2.88 \pm 0.72 * *$ & $6.75 \pm 0.93$ & $6.40 \pm 0.99$ \\
\hline $\mathrm{pO}_{2}(\mathrm{kPa})$ & $8.69 \pm 1.33$ & $9.49 \pm 2.48$ & $7.172 \pm 0.37$ & $10.75 \pm 1.84 * * *$ & $10.06 \pm 2.31$ & $8.46 \pm 2.08$ \\
\hline $\mathrm{HCO}_{3}{ }^{-}(\mathrm{mmol} / \mathrm{l})$ & $31.56 \pm 2.73$ & $31.31 \pm 2.09$ & $26.25 \pm 2.63$ & $15.55 \pm 5.62 * * *$ & $25.28 \pm 1.29$ & $28.8 \pm 2.11 * * *$ \\
\hline st. $\mathrm{HCO}_{3}{ }^{-}(\mathrm{mmol} / \mathrm{l})$ & $26.67 \pm 1.72$ & $26.55 \pm 2.0$ & $24.16 \pm 1.24$ & $20.07 \pm 4.65^{*}$ & $22.95 \pm 1.37$ & $27.04 \pm 1.91 * * *$ \\
\hline $\mathrm{satO}_{2}(\%)$ & $87.3 \pm 8.9$ & $87.8 \pm 10.3$ & $84.66 \pm 2.95$ & $93.3 \pm 7.4 * *$ & $89.96 \pm 5.46$ & $89.72 \pm 4.1$ \\
\hline $\mathrm{BE}(\mathrm{mmol} / \mathrm{l})$ & $4.4 \pm 1.63$ & $4.65 \pm 0.59$ & $0.06 \pm 1.71$ & $-5.23 \pm 6.34^{*}$ & $-1.17 \pm 1.28$ & $2.78 \pm 0.94 * * *$ \\
\hline BB (mmol (l) & $51.56 \pm 2.23$ & $51.13 \pm 2.82$ & $48.34 \pm 1.71$ & $42.44 \pm 6.65 *$ & $46.39 \pm 1.56$ & $50.21 \pm 1.34 * * *$ \\
\hline $\mathrm{ctO}_{2}(\mathrm{mmol}(\mathrm{l})$ & $9.22 \pm 2.29$ & $10.28 \pm 2.72$ & $8.03 \pm 0.29$ & $20.05 \pm 0.56^{* * *}$ & $18.58 \pm 1.34$ & $19.17 \pm 1.05$ \\
\hline $\mathrm{Na}^{+}(\mathrm{mmol} / \mathrm{l})$ & $145.1 \pm 2.1$ & $143.2 \pm 2.7^{*}$ & $140.0 \pm 6.75$ & $134.2 \pm 5.6$ & $127.97 \pm 21.84$ & $128.58 \pm 23.45$ \\
\hline $\mathrm{K}^{+}(\mathrm{mmol} / \mathrm{l})$ & $4.69 \pm 0.31$ & $4.63 \pm 0.3$ & $6.81 \pm 1.43$ & $8.85 \pm 1.31 *$ & $5.00 \pm 0.71$ & $4.68 \pm 0.5$ \\
\hline $\mathrm{Ca}^{2+}(\mathrm{mmol} / \mathrm{l})$ & $1.31 \pm 0.05$ & $1.33 \pm 0.05$ & $2.14 \pm 0.07$ & - & $0.99 \pm 0.44$ & $0.996 \pm 0.38$ \\
\hline $\mathrm{Cl}^{-}(\mathrm{mmol} / \mathrm{l})$ & $100.1 \pm 1.21$ & $100.51 \pm 2.43$ & $110.2 \pm 2.39$ & & $104.8 \pm 5.2$ & $101.06 \pm 5.1 *$ \\
\hline
\end{tabular}

Data presented as mean $\pm \mathrm{SD} .{ }^{*} \mathrm{p}<0.05, * * \mathrm{p}<0.01$ and $* * * \mathrm{p}<0.001$ statistically significant differences between light and dark period. $\mathrm{pCO}(\mathrm{kPa})$ - partial pressure of carbon dioxide, $\mathrm{pO}_{2}(\mathrm{kPa})$ - partial pressure of oxygen, $\mathrm{HCO}_{3}{ }^{-}(\mathrm{mmol} / \mathrm{l})$ - hydrogen carbonate, $\mathrm{stHCO}_{3}{ }^{-}(\mathrm{mmol} / \mathrm{l})-\mathrm{standard}$ hydrogen carbonate, $\mathrm{ctCO}_{2}(\mathrm{mmol} / \mathrm{l})$ - total amount of carbon dioxide, BE $(\mathrm{mmol} / \mathrm{l})$ - base excess, $\mathrm{BB}(\mathrm{mmol} / \mathrm{l})$ - total buffer base, ctO ${ }_{2}-\mathrm{total}^{\mathrm{amount}}$ of oxygen, satO $\mathrm{O}_{2}(\%)-$ saturation of hemoglobine by oxygen

\section{2. $\mathrm{pCO}_{2}$}

Significant LD differences in $\mathrm{pCO}_{2}$ were found under $\mathrm{K} / \mathrm{X}$ anaesthesia but not under $\mathrm{P}$ and $\mathrm{Z}$ anaesthesias (table 3). In both light parts of the rat regimen day, significant hypercapnia occurred under $\mathrm{P}$ and $\mathrm{Z}$ anaesthesias. More pronounced hypokapnia was found under $\mathrm{K} / \mathrm{X}$ anaesthesia in the dark part. In the light part, there was a significant difference between $\mathrm{P}$ and $\mathrm{Z}$ anaesthesia $(\mathrm{p}<0.001)$, with higher values in $\mathrm{P}$ anaesthesia. In the dark part of the rat regime day, significant differences between all selected types of anaesthesia (P vs. K/X [p $<0.001]$; P vs. Z [p $<$ $0.01]$; and $\mathrm{K} / \mathrm{X}$ vs. $\mathrm{Z}[\mathrm{p}<0.001])$ were observed. Because the $\mathrm{pCO}_{2}$ ranges $(4.44-5.62 \mathrm{kPa}$ from table 1) are considered to be physiological compared with these ranges, the mean $\mathrm{pCO}_{2}$ reported in this study is in the range of hypercapnia for each type of anaesthesia in both light parts, except $\mathrm{K} / \mathrm{X}$ anaesthesia in the dark part of the rat day.

\section{3. $\mathrm{pO}_{2}$}

Similar to $\mathrm{pH}, \mathrm{LD}$ differences in $\mathrm{pO}_{2}$ were only significant in $\mathrm{K} / \mathrm{X}(\mathrm{p}<0.001)$ and $\mathrm{Z}(\mathrm{p}<0.05)$ anaesthesias (table 3$)$. However, it is interesting to note that for all types of general anaesthesia used in this study, hypoxia was detected in spontaneously breathing rats in both light parts of the rat regimen day (11.921 $-15.13 \mathrm{kPa}$ from table 1). Statistically significant differences were found in a light part between $\mathrm{P}$ and $\mathrm{K} / \mathrm{X}(\mathrm{p}<0.001), \mathrm{P}$ and $\mathrm{Z}(\mathrm{p}<0.05)$, and between $\mathrm{K} / \mathrm{X}$ and $\mathrm{Z}$ anaesthesia $(\mathrm{p}<0.001)$, with the lowest values under $\mathrm{K} / \mathrm{X}$ anaesthesia. In the dark part, more pronounced hypoxia was under $Z$ anaesthesia $(p<0.05)$ compared with $K / X$ anaesthesia. Differences between $\mathrm{P}$ and $\mathrm{Z}$ anaesthesias were not found.

\section{4. $\mathrm{HCO}_{3}^{-}, \mathrm{O}_{2}$ Saturation, Buffer Systems}

Significant $\mathrm{LD}$ differences in $\mathrm{HCO}_{3}{ }^{-}$were detected under 
$\mathrm{K} / \mathrm{X}$ and $\mathrm{Z}$ anaesthesias (table 3 ). Taking into account that the normal range of bicarbonate $(23.8-26.8 \mathrm{mmol} / 1$ from table 1$)$, increased levels were measured in $\mathrm{P}$ anaesthesia, which would correspond to metabolic alkalosis in both light parts of the regimen. Normal levels were detected in $\mathrm{Z}$ anaesthesia in both lighted parts. In $\mathrm{K} / \mathrm{X}$ anaesthesia, the levels of $\mathrm{HCO}_{3}{ }^{-}$were dependent on the cycle of alternating light and dark. Under this type of anaesthesia, in the light part, values moved around the normal range; however, in the dark part of the day, levels were reduced to what corresponds to metabolic acidosis. Between individual anaesthetics, significant differences were found, especially in the dark part of the rat regimen day.

Significant LD differences in total buffer bases (BB) and base excess (BE) were found in $\mathrm{K} / \mathrm{X}$ and $\mathrm{Z}$ anaesthesias (table 3). $\mathrm{BB}$ moves from 40 to $60 \mathrm{mmol} / \mathrm{l}$ in all types of anesthesia and the $\mathrm{BE}$ from -8 to $+12 \mathrm{mmol} / 1$ in both light parts of the rat regimen day under all types of anesthesia. Saturation of hemoglobin by oxygen was practically the same in all types of general anaesthesia, and significant LD differences were not found except for $\mathrm{K} / \mathrm{X}$ anaesthesia, with higher saturation in the dark part of the rat regimen day.

\subsection{Ions}

LD differences for plasma $\mathrm{Na}^{+}$concentration were not detected under any of the selected general anaesthesias (table 3). The highest $\mathrm{Na}^{+}$concentrations $\left(\mathrm{Na}^{+} 137.4-140.7 \mathrm{mmol} / 1\right.$ from table 2) were under $\mathrm{P}$ anaesthesia in the both light parts of the rat regimen day (light $\mathrm{P}$ vs. $\mathrm{K} / \mathrm{X}, \mathrm{p}<0.01$; P vs. $\mathrm{Z}, \mathrm{p}<$ 0.01 ; dark $\mathrm{P}$ vs. $\mathrm{K} / \mathrm{X}, \mathrm{p}<0.01$; and nonsignificantly higher compared with $\mathrm{Z}$ anaesthesia). In the light part of the day, the highest plasma concentration of $\mathrm{Na}^{+}$was recorded under $\mathrm{P}$ anaesthesia and the lowest concentration in $\mathrm{Z}$ anaesthesia but with increasing dispersion of values. Based on presented findings, it appears probable that the distribution of $\mathrm{Na}^{+}$ions is significantly influenced by $\mathrm{Z}$ anaesthesia. Under $\mathrm{P}$ anaesthesia, regardless of the light or dark part of the day, hypernatremia was detected. In $\mathrm{K} / \mathrm{X}$ and $\mathrm{Z}$ anaesthesia, mean plasma $\mathrm{Na}^{+}$ concentrations moved from hyponatremic to hypernatremic.

Significant (i.e., $\mathrm{p}<0.01$ ) LD differences in plasma $\mathrm{K}^{+}$ concentration were found only under $\mathrm{K} / \mathrm{X}$ anaesthesia, with higher values during the dark part of the rat regimen day (table 3 ). Under this type of anaesthesia, the mean value was significantly higher $(\mathrm{p}<0.001)$ compared with both $\mathrm{P}$ and $\mathrm{Z}$ anaesthesias in both light parts of the day. Moderate hyperkalemia $\left(\mathrm{K}^{+} 3.9-4.2 \mathrm{mmol} / \mathrm{l}\right.$ from table 2$)$ was detected under $\mathrm{P}$ and $\mathrm{Z}$ anaesthesias in both light parts of rat regimen day.

Similar to $\mathrm{Na}^{+}$, no significant LD differences in plasma $\mathrm{Ca}^{2+}$ concentrations were found (table 3). Under $\mathrm{P}$ and $\mathrm{Z}$ anaesthesias, plasma concentrations of $\mathrm{Ca}^{2+}$ were practically the same. In the light part of the day under $\mathrm{K} / \mathrm{X}$ anaesthesia, there was a significantly $(\mathrm{p}<0.001)$ higher $\mathrm{Ca}^{2+}$ concentration versus $\mathrm{P}$ and $\mathrm{Z}$ anaesthesias. In the dark part of the day under $\mathrm{K} / \mathrm{X}$ anaesthesia, the values were out of range of the ABL 800 Flex ion analyzer. Although significant differences were found between the different types of anaesthesia in both light parts of the day, the animals were in relatively severe state of hypocalcemia (range $1.13-1.32 \mathrm{mmol} / \mathrm{l}$ ), especially when under $\mathrm{P}$ and $\mathrm{Z}$ anaesthesias.

A significant (i.e., $p<0.05$ ) LD difference in plasma concentrations of $\mathrm{Cl}^{-}$was found only under $\mathrm{Z}$ anaesthesia (table 2). Hypochloremia (103.7 - $107.9 \mathrm{mmol} / \mathrm{l}$ from table 2) occurred under $\mathrm{P}$ anaesthesia in both light parts of the rat regimen day. Normochloremia to hyperchloremia occurred under both $\mathrm{K} / \mathrm{X}$ and $\mathrm{Z}$ anaesthesias in both light parts of the rat regimen day. In the dark part of the day under $\mathrm{K} / \mathrm{X}$ anaesthesia, the values were out of the detection range of the ABL 800 Flex ion analyzer.

\section{Discussion}

\section{1. $\mathrm{pH}$}

In anaesthetized rats, there is considerable respiratory depression resulting in lower $\mathrm{pH}$ and higher $\mathrm{pCO}_{2}[25,5]$. Taking into account that the values in table 1 found by mentioned authors are considered like physiological, compared to these ranges, the $\mathrm{pH}$ values from experiments range from mild acidosis to normal values for each type of anaesthesia, not only in the light, but even in the dark part of the day.

Acidic conditions were detected in $\mathrm{P}$ anaesthesia in both lighted parts of the rat regime day. $\mathrm{P}$ anaesthesia is likely to produce a more acidic environment than $\mathrm{K} / \mathrm{X}$ and $\mathrm{Z}$ anaesthesia, and although the LD difference in $\mathrm{P}$ anaesthesia was not recorded, the $\mathrm{pH}$ values were the lowest in both lighted parts of the rat regime day. Consequently, the effect of $\mathrm{P}$ anaesthesia is likely to have the same and immediate effect on the buffering activity of the buffer systems or on the regulatory mechanisms involved in maintaining the isohydria independently of the light and dark cycle.

From the chronobiological point of view, it was concluded that $\mathrm{P}$ anaesthesia is not the most appropriate type of anaesthesia. Initially, acidosis is induced, regardless of the synchronization of the animals to the light-dark cycle, and therefore it is not possible to follow periodic changes in the functions of the individual systems that are primarily dependent on changes in the extracellular $\mathrm{pH}$. Therefore, $\mathrm{K} / \mathrm{X}$ and $\mathrm{Z}$ anaesthesia may be more appropriate anaesthesia as the average arterial $\mathrm{pH}$ values are within the range of isohydria. This assumption only applies if the rats are anaesthetized in the dark (active) part of their regime day.

\section{2. $\mathrm{pCO}_{2}$}

Taking into account that the values in table 1 found by mentioned authors are considered like physiological, compared to these ranges, the $\mathrm{pCO}_{2}$ values are more or less in the range of hypercapnia for each type of anaesthesia, not only in light but also in dark day of the day. P anaesthesia is likely to form a more pronounced hypercapnia compared to $\mathrm{K} / \mathrm{X}$ and $\mathrm{Z}$ anaesthesia, irrespective of the light-dark cycle.

\section{3. $\mathrm{pO}_{2}$}

On comparing experimental results with previously quoted 
value ranges, spontaneously breathing rats under pentobarbital anaesthesia were found to exhibit systemic acidosis, hypoxia and hypercapnia in the light as well as in the dark period of the rat regimen day, but with elimination of the LD differences. Although the disruptive effect of acute hypoxia on circadian rhythms has been described [26, 27, 28, 29, 30], it appears that this effect can be evident in rats under pentobarbital anaesthesia. Hypoxia modifies the circadian oscillations of important variables, such as body temperature and metabolism, may lead to the expectation that the daily rhythms of many functions are disrupted by hypoxia according to their relationships and connection with the primary variables. Moreover, hypoxic state likely contributes a larger parasympathetic influence on the heart. Similarly, the disruptive effect of ketamine on circadian rhythms has been described by others [31, 32], this effect was associated with modification, no with loss, of acrophase, amplitude or mesor.

\subsection{Bicarbonates}

The relationships between acid-base balance and ion management are closely connected. The main reason is that one part of the bicarbonate buffer has no charge $\left(\mathrm{H}_{2} \mathrm{CO}_{3}\right.$ [i.e., $\left.\left.\mathrm{CO}_{2}\right]\right)$, while the second component is charged $\left(\mathrm{HCO}_{3}\right)$. Therefore, the bicarbonate anion must be in equilibrium with other ions to preserve electroneutrality in the internal environment. For partial pressure of $\mathrm{CO}_{2}$, this does not apply, and therefore, its regulation can be largely independent. According to the Henderson-Hasselbach equation, the $\mathrm{pH}$ of the internal environment depends on the ratio of bicarbonate concentration to $\mathrm{pCO}_{2}$. Regarding the regulation of most major ions $\left(\mathrm{Na}^{+}, \mathrm{K}^{+}\right.$, $\mathrm{Cl}^{-}$), these regulations are very sensitive but have only limited possibilities for rapid influence, resulting in serious functional consequences for the organism. In this case, if the concentration of a particular ion alters some pathological process, this change must be compensated by a change in the concentration of another ion to maintain electrical neutrality. Often, this compensation is afforded by changes in bicarbonate concentration. Biocarbonates, regardless of blood $\mathrm{pH}$, alter the transcellular distribution of $\mathrm{K}^{+}$, reflecting the utility of hydrogen carbonate therapy in hyperkalemia, even in conditions of compensated blood $\mathrm{pH}$ [33].

Experimental measurements indicated elevated levels of bicarbonate under $\mathrm{P}$ anaesthesia, which, compared with the normal range (23.8-26.78 $\mathrm{mmol} / \mathrm{l}$ in rats), would correspond to metabolic alkalosis, unless there were changes in other parameters of acid-base balance in both light parts of the day. However, under $\mathrm{P}$ anaesthesia, relatively severe acidosis, hypercapnia, hyperkalemia, and hypochloremia were found, which could signal the compensation of this state or the replacement of chlorides in the blood by bicarbonates. In this regard, $\mathrm{P}$ anaesthesia induces more serious disruption of acid-base balance, independent of the cycle of alternating light and darkness. In $\mathrm{K} / \mathrm{X}$ and $\mathrm{Z}$ anaesthesias, these changes were more subtle, and when LD differences appear to be preserved, it is assumed that circadian rhythms are also preserved, and therefore, from a chronobiological point of view, these are appropriate types of general anaesthesia.

\section{5. $B E$ and $B B$}

$\mathrm{BE}$ relates to a true excess of base in the range (above or below) of the total BB. Normally, BB is $48-49 \mathrm{mmol} / \mathrm{l}$. If BB is $40 \mathrm{mmol} / \mathrm{l}$, it means that the buffer base was decreased by almost $8 \mathrm{mmol} / \mathrm{l}$ or $\mathrm{BE}$ is $-8 \mathrm{mmol} / \mathrm{l}$ (also known as base deficiency). If BB is $60 \mathrm{mmol} / \mathrm{l}$, it indicates that the base of the buffer is increased by approximately $12 \mathrm{mmol} / \mathrm{l}$, or BE is +12 $\mathrm{mmol} / \mathrm{l}$. Fifty percent of $\mathrm{BB}$ is produced by bicarbonate and $25 \%$ by other buffers (proteins, phosphates, sulfates). In presented experiments, $\mathrm{BE}$ and the total $\mathrm{BB}$ moved within the normal ranges, which would mean that buffering capacity was sufficient not only in the dark but also in the light period of the rat regimen day and under all types of anesthesia.

\subsection{Ions}

Acidemia leads to hyperkalemia. The total amount of potassium in the body does not increase, and it only changes its distribution between compartments. From a whole-body perspective, potassium depletion will be a consequence of acidity, because its renal loss increases (so that heavier and longer-lasting acidosis will be accompanied by depletion of potassium at the current hyperkalemia). Similarly, alkalemia is accompanied by hypokalemia. However, the entire mechanism also works inversely: hyperkalemia causes acidosis and hypokalemia, on the other hand, leads to alkalosis. Simplified, potassium cations that move through the plasma membrane are exchanged for protons.

From the chronobiological point of view, however, this was not confirmed by presented results. In each type of anaesthesia, hyperkalemia was recorded, irrespective of whether the measurements were made in the light or dark part of the rat regimen day. Acidosis occurred only in the light part of the day under each type of anaesthesia, while in the dark part of the day, the $\mathrm{pH}$ values also moved within normal ranges, but only under $\mathrm{K} / \mathrm{X}$ and $\mathrm{Z}$ anaesthesias These findings should, therefore, be taken into account to avoid application of particular anaesthesias in the light part of the rat regimen day because positive correlations between $\mathrm{pH}$ and plasma $\mathrm{K}^{+}$concentration have been calculated for all types of anaesthesia (P light $\mathrm{r}=0.41, \mathrm{P}$ dark $=0.16 ; \mathrm{K} / \mathrm{X}$ light $\mathrm{r}=0.57, \mathrm{~K} / \mathrm{X}$ dark $\mathrm{r}=0.01, \mathrm{Z}$ light $\mathrm{r}$ $=0.79$, dark $\mathrm{r}=-0.22$ ). What this means that the increase in plasma concentration $\mathrm{K}^{+}$shifts the $\mathrm{pH}$ to the alkalinity, respectively. Alkalosis increases $\mathrm{K}^{+}$leakage if the rat is in general anaesthesia. In the dark part of the rat regimen day, no $\mathrm{pH}$ dependence on $\mathrm{K}^{+}$was found under all types of anaesthesia.

\section{Conclusion}

After summarizing the results from the analysis of acid-base balance parameters and ion concentrations from blood plasma (table 4), it was concluded that there are differences in the final status of the rat internal environment that depend on the LD cycle and on the type of anaesthesia. In the light part of the day, under $\mathrm{P}$ anaesthesia, the rats are in a 
state of acidosis, hypercapnia, and hypoxia, and elevated levels of bicarbonate have been reported. Similarly, it is also in the dark, but with mild acidosis, hypercapnia and hypoxia with a moderate decrease to normal $\mathrm{pO}_{2}$ values but with elevated levels of bicarbonate. Saturation of hemoglobin by oxygen was at the same level in both light parts of the rat regimen day, and at approximately $87 \%$, the efficiency of the buffer system was not impaired because the values were within the normal range. Under $\mathrm{K} / \mathrm{X}$ anaesthesia, a dependence on LD cycle in all monitored parameters was found. Acidosis, normocapnia to hypercapnia, hypoxia, and a relatively large range of bicarbonate levels moved from reduced to increased levels by comparison with ranges in the light part of the day. In the dark part of the day, from normal to alkaline $\mathrm{pH}$, hypocapnia, moderate decreased to normal $\mathrm{pO}_{2}$ but with a reduced level of bicarbonate. Different values were in saturation of hemoglobin by oxygen, where higher saturation was during the dark (active) part (around 90\%). The efficiency of the buffer system moved within the normal range in both light parts of the day. Under $\mathrm{Z}$ anaesthesia, the status was as follows: acidosis, hypercapnia, hypoxia to normoxia, and normal levels of bicarbonate in the light part of the day. In the dark part of the day, the state of the internal environment was from acidic to normal, hypercapnia, and $\mathrm{pO}_{2}$ moved from mild hypoxia to normoxia at a normal to moderately elevated level of bicarbonate. The saturation of hemoglobin by oxygen fluctuated around $89 \%$ in both light parts of the rat regimen day, and $\mathrm{BB}$ and $\mathrm{BE}$ were also in the normal range; thus, buffering capacity remained intact.

Table 4. Status of acid-base balance and ions concentrations based on average values after 20 minutes from the administration of the anaesthetic agents.

\begin{tabular}{ll}
\hline & \multicolumn{1}{c}{ Status } \\
\hline $\mathrm{P}$ - light & Acidosis, hypoxia, hypercapnia, increased level of $\mathrm{HCO}_{3}^{-}$, hypernatremia, hyperkalaemia, normocalcemia, hypochloremia \\
$\mathrm{P}-$-dark & Acidosis, hypoxia, hypercapnia, increased level of $\mathrm{HCO}_{3}^{-}$, hypernatremia, hyperkalaemia, normocalcemia, hypochloremia \\
$\mathrm{K} / \mathrm{X}$ - light & Acidosis, hypoxia, hypercapnia, normal level of $\mathrm{HCO}_{3}^{-}$, normonatremia, hyperkalemia, hypercalcemia, hyperchloremia \\
$\mathrm{K} / \mathrm{X}$ - dark & Alkalosis, hypoxia, hypocapnia, decreased level of $\mathrm{HCO}_{3}^{-}$, hyponatremia, hyperkalaemia, \\
$\mathrm{Z}$ - light & Acidosis, hypoxia, hypercapnia, normal level of $\mathrm{HCO}_{3}^{-}$, hyponatremia, hyperkalaemia, hypocalcemia, normochloremia \\
$\mathrm{Z}$ - dark & Normal pH, hypoxia, hyprecapnia, increased level of $\mathrm{HCO}_{3}^{-}$, hyponatremia, hyperkalaemia, hypocalcemia, hypochloremia \\
\hline
\end{tabular}

\section{References}

[1] Subramanian RK, Sidharthan A, Maneksh D, Ramalingam L, Soosai Manickam A, Kanthakumar P, Subramani S (2013) Normative data for arterial blood gas and electrolytes in anesthetized rats (Letter). Ind J Pharmacol 45: 103-104.

[2] De Oliveira RB, De Macedo DV, Santos GB, Arcanjo AM (2012) Reliability of the electrocardiogram in normal rats. International Journal of Exercise Science: Conference Proceedings 1: Article 63.

[3] Lewis LD, Ponten U, Siesjo BK (1973) Arterial acid-base changes in un-anesthetized rats in acute hypoxia. Respir Physiol 19: 312-21.

[4] Pepelko WE, Dixon GA (1975) Arterial blood gases in conscious rats exposed to hypoxia, hypercapnia, or both. J Appl Physiol 38: 581-587.

[5] Brun-Pascaud M, Gaudebout C, Blayo MC, Pocidalo JJ (1982) Arterial blood gases and acid-base status in awake rats. Respir Physiol 48: 45-57.

[6] Girard P, Brun-Pascaud M, Pocidalo JJ (1983) Acid-base status of awake rats after cannulation of aorta and vena cava. Kidney Int 24: 795-799.

[7] Hess L, Dvořáček I, Svobodník J (1988) Anesthesia of laboratory animals, Prague: Avicenum. Chapter 3, Rats (Rodentia); p. 158.

[8] Dettmers Ch, Hagendorff A, Kastrup A, Luderitz B, Hartmann A (1994) An experimental model for hemodynamic evaluation of arrhythmias in rats. Cerebrovasc Dis 4: 309-313.

[9] Chi OZ, Wei HM, Tse J, Klein SL, Weiss HR (1996) Cerebral microregional oxygen balance during chronic versus acute hypertension in middle cerebral artery occluded rats. Anesth

Analg 82: 587-592.

[10] Ohoi I, Takeo S (1996) Involvement of superoxide and nitric oxide in the genesis of reperfusion arrhythmias in rats. Eur $\mathrm{J}$ Pharmacol 306: 123-131.

[11] Schultz JJ, Hsu AK, Gross GJ (1997) Ischemic preconditioning and morphine-induced cardioprotection involve the delta

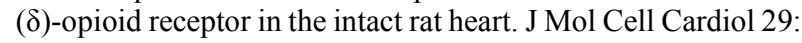
2187-2195.

[12] Sun W, Wainwright CL (1997) The role of nitric oxide in modulating ischaemia-induced arrhythmias in rats. $\mathrm{J}$ Cardiovasc Pharmacol 29: 554-562.

[13] Forkel J, Chen X, Wandinger S, Keser F, Duschin A, Schwanke U, Frede S, Massoudy P, Schulz R, Jakob H, Heusch G (2004) Responses of chronically hypoxic rat hearts to ischemia: $\mathrm{K}_{\mathrm{ATP}}$ channel blockade does not abolish increased RV tolerance to ischemia. Am J Physiol Heart Circ Physiol 286: H545-H551.

[14] Valenza F, Pizzocri M, Salice V, Chevallard G, Fossali T, Coppola S, Froio S, Polli F, Gatti S, Fortunato F, Comi GP, Gattinoni L (2012) Sodium bicarbonate treatment during transient or sustained lactic acidemia in normoxic and normotensive rats. PLoS ONE 7: e46035.

[15] Peralta-Ramírez A, Raya AI, Pineda C, Rodríguez M, Aguilera-Tejero E, López I (2014) Acid-base balance in bremic bats with bascular balcification. Nephron Extra 4: 89-94.

[16] Luo X, Yin Y, You G, Chen G, Wang Y, Zhao J, Wang B, Zhao L, Zhou H (2015) Gradually increased oxygen administration improved oxygenation and mitigated oxidative stress after resuscitation from severe hemorrhagic shock. Anesthesiology 123: 1122-1132.

[17] Menegon LF, igueiredo JF, Gontijo JAR (1998) Effect of metabolic acidosis on renal tubular sodium handling in rats as determined by lithium clearance. Braz J Med Biol Res 31: 1269-1273. 
[18] Da Silva Costa EC, Gonçalves AA, Areas MA, Morgabel RGB (2008) Effects of metformin on QT and QTc interval dispersion of diabetic rats. Arq Bras Cardiol 90: 232-238.

[19] Kim JA, Choi HJ, Kwon YK, Ryu DH, Kwon TH, Hwang GS (2014) ${ }^{1} \mathrm{H}$ NMR-based metabolite profiling of plasma in a rat model of chronic kidney disease. PLoS ONE 9: e85445.

[20] Dispersyn G, Pain L, Challet E, Touitou Y (2008) General anesthetics effects on circadian temporal structure: An Update. Chronobiol Int 25: 835-850.

[21] Reinberg A (1986) Circadian rhythms in effects of hypnotics and sleep inducer. Int J Clin Pharmacol Res 6: 33-44.

[22] Sato Y, Seo N, Kobahashi E (2005) The dosing-time dependent effects of intravenous hypnotics in mice. Anesth Analg 101: $1706-1708$.

[23] Haskins SC, Patz JD, Farver T. (1986) Xylazine and xylazine-ketamine in dogs. Am J Vet Res 47: 636-641.

[24] Farver TB, Haskins SC, Patz JD (1986) Cardiopulmonary effects of acepromazine and of the subsequent administration of ketamine in the dog. Am J Vet Res 47: 631-635.

[25] Kaczmarczyk G, Reinhardt HW (1975) Arterial blood gas tensions and acid-base status of wistar rats during thiopental and halothane anesthesia. Lab Anim Sci 25: 184-190.

[26] Mortola JP, Seifert EL (2000) Hypoxic depression of circadian rhythms in adult rats. J Appl Physiol. 88: 365-368.
[27] Bishop B, Silva G, Krasney J, Nakano H, Roberts A, Farkas G, Rifkin D, Shucard D (2001) Ambient temperature modulates hypoxic-induced changes in rat body temperature and activity differentially. Amer J Physiol 280: R1190-R1196.

[28] Bosco G, Ionadi A, Panico S, Faralli F, Gagliardi R, Data P, Mortola JP (2003) Effects of hypoxia on the circadian patterns in men. High Alt Med Biol 4: 305-318.

[29] Kaplan JL, Gao E, Garavilla L, Victain M, Minczak B, Dalsey WC (2003) Adenosine A1 antagonism attenuates atropine-resistant hypoxic bradycardia in rats. Acad Emerg Med 10: 923-930.

[30] Mortola JP (2007) Hypoxia and circadian patterns. Respir Physiol Neurobiol 158: 274-279.

[31] Prudian F, Gantenbein M, Pelissier AL, Attolini L, Bruguerolle B (1997) Daily rhythms of heart rate temperature and locomotor activity are modified by anaesthetics in rats: a telemetric study. NS Arch Pharmacol 355: 774-778.

[32] Pelissier AL, Gantenbein M, Prudian F, Bruguerolle B (1988) Influence of general anaesthetics on circadian rhythms of heart rate, body temperature and locomotor activity in rats. Sci Tech Ani Lab 23: 91-98.

[33] Fraley DS, Adler S (1976) Isohydric regulation of plasma potassium by bicarbonate in the rat. Kidney International 9: 333-343. https://doi.org/10.1038/ki.1976.39. 